\title{
Technischer Ausschuß für Brillenoptik (Tabo)
}

Nach längerer, durch die Zeitumstände gebotener Pause fand am 25. Nov. 1919 wiederum eine Sitzung des engeren Ausschusses in Berlin statt.

Das Protokoll des Punktes III lautet:

Achsenschéma.

D. Der Vorsitzende gibt Anregungen aus Optikerkreisen kund. Prof. Greeff berichtet daß von den Herren Prof. Henker

Dr. Weiß und ihm auf dem letzten ophthahnologischen Kongreß referiert sei und daß man von den Darlegungen zustimmend Kenntnis genommen habe daß es der Kongreß indes dieser Stelle überlasse weiter zu handeln. Es wird be-schlossen: der frühere sogenannte Rathenower Radbogen auf beiden Halb-kreisen links mit $180>$ und rechts mit 0' wird offiziell angenommen. Er soil TaboGradbogen genannt werden. 